BULLETIN Bulletin hispanique

HISPANIQUE Université Michel de Montaigne Bordeaux

$118-2$ | 2016

Varia

\title{
Prensas y mujeres
}

intervención femenina en la transmisión y la gestión de las imprentas zaragozanas de los siglos XV y XVI

\section{Manuel-José Pedraza-Gracia}

\section{OpenEdition}

Journals

Edición electrónica

URL: http://journals.openedition.org/bulletinhispanique/4622

DOI: 10.4000/bulletinhispanique.4622

ISSN: 1775-3821

Editor

Presses universitaires de Bordeaux

\section{Edición impresa}

Fecha de publicación: 15 diciembre 2016

Paginación: 629-646

ISBN: 979-10-300-0125-9

ISSN: 0007-4640

\section{Referencia electrónica}

Manuel-José Pedraza-Gracia, " Prensas y mujeres », Bulletin hispanique [En línea], 118-2 | 2016,

Publicado el 15 diciembre 2019, consultado el 31 diciembre 2019. URL : http://

journals.openedition.org/bulletinhispanique/4622 ; DOI : 10.4000/bulletinhispanique.4622 


\title{
VARIÉTÉS
}

\section{Prensas y mujeres: \\ intervención femenina en la transmisión y la gestión de las imprentas zaragozanas de los siglos Xv y Xvi*}

\author{
Manuel-José Pedraza-Gracia \\ Universidad de Zaragoza
}

Ce travail étudie la présence des femmes dans les presses de Saragosse durant les XV et $\mathrm{XVI}^{\mathrm{e}}$ siècles, leur fonction d'agents de transmission, de génération en génération, des ateliers d'impression et leur rôle d'imprimeurs lorsqu'elles héritent de l'atelier de leur époux ou de leurs parents.

Mots-clés: femmes, presses, Saragosse, $\mathrm{XV}^{\mathrm{e}}-\mathrm{XVI}^{\mathrm{e}}$ siècles.

Se analiza la presencia de la mujer en la imprenta zaragozana durante los siglos XV y XVI. Se estudia la función de las mujeres como trasmisoras de los talleres de imprenta y como impresoras cando heredan de sus esposos o padres el taller de imprenta.

Palabras clave: mujeres, imprenta, Zaragoza, siglos XV-XVI.

The article analyses the presence of women in Zaragoza's printing press during the 15 th and 16th Centuries. It explores the role of women as transmitters of printing presses or printers when they inherit the printing shop from their husband or father.

Keywords: women, printing press, Zaragoza, 15th-16th Centuries.

A unque se poseen algunas escasas noticias sobre la actividad de las mujeres en la imprenta hispana, como son las referentes a Isabel de Basilea en Salamanca ${ }^{1}$ y a Teresa y Catalina, hijas de Juan de Lucena, en Toledo y la Puebla

* Trabajo realizado con el apoyo del Proyecto de la Secretaría de Estado de Investigación, desarrollo e innovación del Ministerio de Economía y Competitividad FFI2014-55524-P.

1. Vid. A. Rumeau, "Isabel de Basilea: "mujer impresora"», Bulletin Hispanique, 73, 1971, p. 231-247; e «Isabel de Basilea et Alexandre de Canova. Le conflit de 1565-1566», Bulletin Hispanique, 73, 1971, p. 248-262.

Bulletin Hispanique, Tome 118, nº 2 - décembre 2016 - p. 629-646. 
de Montalbán², la función de las mujeres en las indicaciones de responsabilidad de los libros y, particularmente, en la documentación contemporánea conservada, se circunscribe en la inmensa mayoría de los casos a la de familiar, esposa o viuda del impresor. Pero esta circunstancia no resta valor a la presencia de las mujeres en la imprenta ya que paulatinamente se ha ido poniendo de manifiesto que el conocimiento de las mujeres que se encuentran en torno a ese mundo posee mucha más importancia para la comprensión del mismo que la que se le podía suponer; hasta el punto de que el análisis de la actividad de las mujeres en el mundo de la imprenta, del libro y de la lectura se ha convertido en una de las líneas de investigación en historia del libro y de la imprenta que más producción científica viene proporcionando desde hace ya algún tiempo ${ }^{3}$.

2. Vid. F. de los Reyes Gómez, "Juan de Lucena, La Puebla de Montalbán y las imprentas hebreas incunables», Crónicas, 15, 2010, p. 34-37.

3. Se pueden citar algunos de estos estudios que tratan el tema de forma general: S. V. Lenkey, "Printers" wives in the age of humanism», Gutenberg-Jahrbuch, 1975, p. 331-337; Marjorie Dana Barlow, Notes on woman printers in Colonial America and the United States, 1639-1975, New York, Hroswitha Club, 1976; Leona M. Hudak, Early American women printers and publishers, 1639-1820, Metuchen, Scarecrow Press, 1978; Richard L. Demeter, Primer, presses, and composing sticks: women printers of the colonial period, Hicksville, Exposition Press, 1979; Eileen Cadman, Gail Chester, Agnes Pivot, Rolling our own: women as printers, publishers and distributors, London, Minority Press, 1981; Felicity Hunt, "The London trade in the printing and binding of books: an experience in exclusion, dilution and de-skilling for women workers», Women's Studies International Forum, 6, 1983, p. 517-524; Roderick Cave, «The Stockdale sisters revisited: women printers and editors in the West Indies», Printing History, 10, 1988, p. 38-40; Beatrice Hibbard Beech, "Women printers in Paris in the sixteenth century», Medieval Prosopography, 10, 1989, p. 75-93; Georges Duby, Michelle Perrot (dirs.), Geschichte der Frauen, Frankfurt am Main, Büchergilde Gutenberg, 1994; Martha W. Driver, «Women printers and the page, 1477-1541», Gutenberg Jahrbuch, 73, 1998, p. 139-153; Amalia Estrada Porrúa, «Las primeras mujeres de la imprenta novohispana», Libros de México, 53, 1998, p. 25-29; Marina Garone Gravier (comp.), Las otras letras: memorias: mujeres impresoras en la Biblioteca Palafoxiana: ponencias presentadas en la conferencia en Puebla..., Puebla, Biblioteca Palafoxiana, 2008; Manuel-José Pedraza-Gracia, «Las mujeres en la imprenta hispana durante los siglos XV y XVI», en Homenaje a Isabel de Torres Ramirez: estudios de documentación dedicados a su memoria, Granada, Universidad de Granada, 2009, p. 587-606; Marina Garone Gravier i Albert Corbeto López (eds.), Muses de la impremta : la dona i les arts del llibre: segles XVI-XIX, Barcelona, Museu Diocesà de Barcelona, 2009; Elvia Carreño Velázquez (coord.), Ese amoroso tormento: el libro y la mujer novohispana, México, ADABI de México, 2010. Además, se han elaborado investigaciones específicas sobre algunas de estas mujeres impresoras. Por su número se citan solo las referidas a impresoras de la península ibérica: Aristide Rumeau, «Isabel de Basilea: mujer impresora». Bulletin Hispanique, 73, 1971, p. 231-247; Clive Griffin, «Brígida Maldonado 'ymprimidora' sevillana, viuda de Juan Cromberger», Archivo Hispalense, 76-233, 1993, p. 83-117; Mónica Cortés Corral, Victoria Méndez Viar, «Impresoras madrileñas en el Siglo de Oro: Juana Martínez de Angulo», Anexos de Signo, 4, 2001, p. 185-211; María del Mar Fernández Vega, "Jerónima de Gales: una impresora valenciana del siglo XVI», en Pedro Manuel Cátedra García, María Isabel Páiz Hernández, María Luisa López-Vidriero Abello (coords.), La memoria de los libros: estudios sobre la historia del escrito y de la lectura en Europa y América, Salamanca, Instituto de Historia del Libro y de la Lectura, 2004, vol. 1, p. 405-434; Ma. Dolores Sánchez Cobos. «Mariana de Montoya, una mujer impresora en Baeza de comienzos del XVII», en Pedro Manuel Cátedra García, María Isabel Páiz Hernández, María Luisa López-Vidriero Abello (coords.), La memoria de los libros: estudios sobre la historia del escrito y de la lectura en Europa y América, Salamanca, 
No cabe duda de que la consideración en general de la mujer en la sociedad de la época explica lo escaso de su presencia en el negocio del libro. Pero en el estudio del libro y su producción no se puede prescindir de las mujeres, porque sin tener en cuenta a la mitad de la población, las mujeres, como productoras y como usuarias es difícil entender completamente el mundo del libro en la Edad Moderna.

Las mujeres han ejercido diversas labores y funciones dentro del mundo de hombres que es la imprenta. En este trabajo se pretende identificar y ofrecer una perspectiva sobre las mujeres que hicieron que la evolución de la imprenta fuese como realmente fue en la capital del Reino de Aragón en los siglos XV y $\mathrm{XVI}$, porque sin su presencia e intervención no resulta comprensible la historia del libro en Aragón.

\section{LA IMPORTANCIA DE LAS MUJERES EN LA TRANSMISIÓN DE LAS IMPRENTAS}

El común de los negocios artesanales creados durante los siglos XV y XVI se encontraba en pequeños talleres que se constituían en los bajos de las casas, en pequeñas habitaciones de la propiedad del artesano o que poseía en alquiler. Muchas veces estos negocios eran poco más que el núcleo familiar elaborando un producto manufacturado. En esos ambientes resultaría imposible que las mujeres de la familia no tuviesen algún tipo de participación en la elaboración de los productos que se fabrican en la propia casa, tal y como se ha documentado a Isabel de Basilea y a Teresa y Catalina de Lucena. Parece evidente que el contacto permanente con las labores cotidianas familiarizaría a las mujeres de la familia con ellas, por lo que la colaboración en los trabajos del taller debería ser algo natural. Sin embargo, esto no se ha trasmitido en la documentación de la época, salvo en rarísimas excepciones. Esta situación liga a la familia no solo a la vivienda, sino también al negocio. En este ambiente, la desaparición del artesano que conocía el negocio en todas sus facetas era una tragedia familiar y, también, empresarial. En este momento la posición que debían tomar los herederos, especialmente las viudas, podía ser doble: la de perseguir la transmisión del negocio, buscando la subsistencia futura en el capital obtenido por la venta, o la de permanecer en él, rentabilizándolo con el trabajo cotidiano.

El primero de los casos que se relaciona no responde, sin embargo, a este panorama general. Una desconocida para el mundo de la imprenta, Anna Hurus, permite explicar el porqué de una compleja transmisión en el siglo XV.

Instituto de Historia del Libro y de la Lectura, 2004, vol. 1, p. 365-379; Manuel-José PedrazaGracia. "Juana Millán, señora de la imprenta: aportación al conocimiento de una imprenta dirigida por una mujer en la primera mitad del siglo XVI», Bulletin Hispanique, 111-1, 2009, p. 51-73; Ma . Jesús Vázquez Madruga, «Juana Martínez de Angulo: una impresora de Alcalá de Henares a finales del s. XVI», Cuadernos para investigación de la literatura hispánica, 35, 2010, p. 83-102; Rosa M. Gregori Roig, La impresora Jerònima Galés i els Mey (València, segle XVI), València, Generalitat Valenciana, 2012; por ejemplo. 
La primera ocasión en la que la presencia de una mujer es esencial para comprender el traspaso de una imprenta coincide justamente con el de la primera imprenta estable zaragozana, la de los hermanos Hurus, Juan y Pablo. En efecto, en 1499 Pablo Hurus, que ya la regentaba en solitario, debe de encontrarse en la necesidad de elegir entre permanecer en Zaragoza, dedicado a las labores de la imprenta y otros negocios que debía poseer, o volver a Alemania. El humanista converso Gonzalo García de Santa María había dicho ya antes en sus escritos publicados en el propio taller de Pablo Hurus que si yo assi con mi industria como con ruegos no le detuviera, ya se hoviera ido ${ }^{4}$. El taller de Pablo Hurus es el único existente en este momento en el Reino de Aragón. El día 21 de marzo de 1499 Pablo Hurus vende a tres maestros de imprenta de origen alemán, Lope Appentegger, Leonardo Hutz y Jorge Coci:

Todos los aperos et exercicios que yo tengo en la ciudat de Çaragoça para fazer libros de enprenta, como son prensas, letras, estanyo e matrizes e ponçones, figuras e otras qualesquiere instrumentos pertenecentes al officio de la dicha enprenta, los quales yo agora tengo dentro de unas casas que son de don Francisco Palomar e que son sitas en la parroquia de San Gil... Item mas, vos bendo todos e qualesquiere bienes mobles estantes dentro de las dichas casas como son ropas de lechos, la fusta de aquellos, ensemble con qualesquiere caxas, con la fusteria que tengo dentro de aquellas, excepto libros e paper...

Pero, ¿quiénes son estos tres maestros alemanes? $\mathrm{Coci}^{6}$ y $\mathrm{Hutz}^{7}$ eran impresores criados y oficiales de confianza de la imprenta de Hurus, incluso Hutz había poseído imprenta propia en otros lugares de la Península ${ }^{8}$; esto es, seguramente son los únicos posibles compradores a los que se podría vender una imprenta en la ciudad, las únicas personas que entenderían del negocio en Zaragoza, gentes que ya estaban formadas en el oficio. Sin embargo,

4. Cf. Leonardo Romero Tobar, «Los libros poéticos impresos en los talleres de Juan y Pablo Hurus", Aragón en la Edad Media, 8, 1989, número monográfico homenaje al profesor emérito Antonio Ubieto Arteta, p. 561-574.

5. A. H. Prot. Z., Protocolo de Juan de Aguas, 1499, f. 39v. Cf. Manuel-José PedrazaGracia, «El traspaso de la imprenta de Pablo Hurus: aportación documental para el estudio de la imprenta incunable zaragozana", Boletín del Museo e Instituto "Camón Aznar», 68, 1997, p. 131-142, doc. 3 .

6. Jorge Coci, alemán de Constanza, figura documentado por primera vez en 1492 en una procura de Pablo Hurus para presentar carta de franqueza con el nombre de Georgio Koch de Constanza, junto con Voolff Appentegger de Constanza -su socio en 1499-, Gaspar von Buel de Sant Gallen y Paulo de Prusia. (A. H. Prot. Z., Protocolo de Antón Mauran, 1492, s.f.). R. S. Janke, «Algunos documentos sobre Pablo Hurus y el comercio de libros en Zaragoza a fines del siglo XV", Príncipe de Viana, 47, 1986, anejo 2, Homenaje a José María Lacarra, p. 335-349; p. 339, nota 17 .

7. Leonardo Hutz, que también figura en algunas obras como Leonardo Alemán, era impresor de profesión y había participado en diversas sociedades de impresores con muy escasa fortuna. Entre 1491 y 1495 imprimió en Valencia asociado con el impresor alemán Pedro Hagenbach para el editor Jaime Vila. Desde 1494 hasta 1497 se estableció en Salamanca, donde imprimió a partir de 1496 con Lope Sanz. Parece que Hagenbach debió concluir los trabajos contratados por ambos en Valencia en ese periodo de tiempo en que su actividad coincide en ambas ciudades.

8. Vid. nota 7. 
Lope Appentegger ${ }^{9}$ era un mercader-comerciante instalado en Zaragoza, seguramente también representante de las compañías alemanas que negociaban con productos peninsulares y centroeuropeos construyendo así un círculo con las idas y venidas de mercancía, e hijo de Anna Hurus y Ludwig Appentegger; de modo que el tercero de los componentes de la sociedad de impresores que adquiere y sucede a Hurus en su imprenta de Zaragoza era hijo de la hermana del vendedor. Es perfectamente comprensible que Hurus dejase como copropietario de la imprenta a su sobrino por tres razones: la primera, con objeto de ofrecer una mínima renta (la proporcionada por el negocio que se vendía a un miembro de su familia que se independizaba y quedaba en Zaragoza en solitario desde ese momento); en segundo lugar, para garantizarse el pago del precio aplazado por la venta del negocio, sin temor de que los otros dos socios y compradores desaparecieran con el material de la imprenta sin haber satisfecho las deudas contraídas con el tío ${ }^{10}$; y, por último y en tercer lugar, para dejar un representante que cerrase los otros negocios que le quedaban en Zaragoza. En suma, Pablo Hurus dejaba como sucesor (representante) en todos los negocios que pudiesen quedar por finalizar de Zaragoza a su sobrino (nótese que Hurus excluye específicamente los libros ya impresos y el papel, debido, con seguridad, a su fácil comercialización). El contrato de compraventa se pacta de forma retroactiva a la Navidad de 1498, y se establece un precio de venta de 450 florines que se pagan en la ciudad alemana de Constanza, ciudad de la que eran originarios tanto Hurus como Coci, en 4 plazos anuales que vencen entre los años 1499 a 1502: los dos primeros años el plazo monta 125 florines, y los otros dos restantes 100. Como puede apreciarse, la venta se realiza aplazando completamente el total del precio. Es interesante recalcar que, de hecho, Lope Appentegger desaparece del taller en 1502, una vez abonado el total de la deuda, que deja de hallársele en la documentación zaragozana en 1508, sin tener una actividad como impresor de forma evidente, y que fallece en el año1526 en Alemania (Constanza), la ciudad de la que la familia de su madre y sus tíos impresores eran originarios.

No existe, en efecto, una participación directa de Anna Hurus en la compraventa, pero sin ella y la relación familiar que solamente se puede apreciar a través de ella entre su hermano, Pablo, y su hijo, Lope, el negocio no se hubiese pactado en los términos en los que se hizo y, posiblemente, no se hubiese podido llevar a cabo la venta del taller. Hurus debería haber tenido más confianza en los dos impresores, Coci y Hutz, o buscar garantías externas. Es interesante mencionar en este punto que Hurus vende en el documento todos los materiales para el negocio y la existencia más elemental. También podría haberse pactado un pago al contado, lo que seguramente no hubiese podido ser

9. Está documentado por primera vez en Zaragoza el 4 de febrero de 1492 en una carta de procura realizada por su tío Pablo Hurus. A. H. Prot. Z., Protocolo de Antón Mauran, 1492, s.f. Janke, op. cit., p. 339.

10. De esta opinión es F. J. Norton, A descriptive catalogue of printing in Spain and Portugal 1501-1520, Cambridge, Cambridge University Press, 1978, p. 220. 
asumido por parte de los compradores. En cualquiera de estos casos, el nombre de Lope Appentegger jamás hubiese figurado en los datos de impresión de las producciones del taller. Era necesaria la presencia del hijo de Ana Hurus para que el negocio se celebrase de la forma en la que se hizo y, quizás, para que Zaragoza contase con un taller de imprenta durante el largo periodo que va desde 1499 hasta la aparición de la segunda imprenta en Zaragoza treinta años después, la de Pedro Hardouin.

Otras dos mujeres (del mismo nombre y apellido) algunos ańos después ayudan a comprender la evolución de esta misma imprenta, el taller que se ha denominado de la calle de la imprenta. Son Isabel Rodríguez, la esposa de Coci, e Isabel Rodríguez, alias Coci, esposa de Pedro Bernuz.

Desde 1505 Jorge Coci figuró como único propietario de la imprenta que había sido de Pablo Hurus ${ }^{11}$. Pronto contrajo matrimonio con Isabel Rodríguez, hermana del boticario zaragozano Pascual Rodríguez. En 1510 Jorge Coci adquiere unas casas para vivir e instalar la imprenta en la parroquia de San Miguel de los Navarros en el callizo que se llamaba «el primero» o «del arco», que con el transcurso del tiempo pasarán a denominarse, respectivamente, las «casas de la imprenta» y el «callizo de la imprenta».

$\mathrm{Su}$ relación profesional, muy fructífera y estrecha, con el Monasterio Jerónimo de Santa Engracia condujo a que se le concediese una capilla en el Monasterio para ser enterrado él y toda su familia y que se instituyó bajo la advocación de Santa Isabel, esto es, la coincidente con la onomástica de su esposa. Isabel Rodríguez hizo testamento ${ }^{12}$ y falleció en 1536 sin descendencia, lo que forzó a Jorge Coci, que debía de tener ya una edad muy avanzada, a tomar decisiones con respecto a su futuro y, especialmente, sobre sus negocios, buscando retirarse de la actividad comercial y productiva del libro, como lo había hecho su maestro Hurus, puesto que las rentas que podía obtener de las propiedades que poseía y de los negocios enajenados le permitían hacerlo y vivir holgadamente. Jorge Coci murió sin descendencia a comienzos de 1548, once años después de haber tomado la decisión de retirarse.

Pero la figura y la temprana muerte de Isabel Rodríguez tienen gran importancia en esas decisiones que Coci adopta. En un primer momento decide tres actuaciones que lleva a cabo casi inmediatamente después de producirse la

11. Appentegger permaneció, no obstante, en Zaragoza dedicado al comercio, entre otras cosas, de libros hasta 1508, fecha en la que vendió todas sus pertenencias para regresar a Alemania. Murió en su ciudad natal, Constanza, en 1526. Hutz marchó pronto de Zaragoza, ya que en 1505 se le encuentra imprimiendo de nuevo en Valencia, donde, según los colofones, trabajó hasta 1506. Sin embargo, la nueva aventura empresarial de Hutz en Valencia, seguramente costeada con lo obtenido por la venta de la parte que le pudiese quedar de la imprenta zaragozana, debió de ser también un fracaso. Pronto se le vuelve a ver citado en la documentación zaragozana: el 23 de abril de 1507, pero en esta documentación ya no figura como maestro de la imprenta. Se le ha documentado por última vez en Zaragoza en 1519.

12. A.H.Prot.Z. Protocolo de Juan Arruego, 1535, f. 42 y cuad. 
defunción de su esposa: en el mismo año, 1536, vende su librería a Bartolomé de Nájera ${ }^{13}$, y un año después entrega al notario su testamento cerrado ${ }^{14} \mathrm{y}$ vende a:

...Bartholome de Najara, librero, e Paulo Hurus, impresor de libros, habitantes en la dicha ciudat de Caragoça, que presentes soys, para vosotros y a los vuestros, assaber es el exercicio de la enprenta y cosas de aquella, libros, papel y bienes otros infrascriptos y siguientes: primo, todo el exercicio de la emprenta, o imprimiria, como son prensas, letras, estanyo obrado y por obrar, y caxa para componer, y matriçes, y punzones, e instrumentos para fundir o buydar letras, y notas de canto, y mas fusillos para prensas y para ramas, y cinquo camas fornecidas de ropas para obreros, y cinquo caxones grandes, y dos caxas pequenyas, y toda la ferramienta, y cepillos, barrenas, y escoplos, y otras ferramientas que hazen para el arte de la impremiria, y todas las figuras chicas y grandes, y una taça de plata con la qual se sirven los hombre de la impremiria, $y$, en fin, todo lo otro que esta en la casa de la emprenta y sirve para el exercicio de la emprenta... por precio de ocho mil sueldos, digo quatrozientas libras... ${ }^{15}$

A todo lo anterior deben añadirse una cantidad importante de papel y numerosos libros cuyo precio se estimó, una vez añadido lo que montaba el coste de la imprenta, en 47.101 sueldos y 4 dineros jaqueses. Los compradores reconocieron el pago de la mencionada cantidad mediante una comanda que se pactó el mismo día ante notario. Precisamente este último documento es el que de acuerdo a los fueros de 1528 firmaron de su mano ${ }^{16}$ ambos compradores: Bartolomé de Nájera ${ }^{17}$ y Pablo Hurus, que se reconocieron como habitantes en

13. El comprador es Bartolomé de Nájera, que ya se encargaba de la librería de Coci como criado suyo. La librería estaba situada en la calle de las Botigas Hondas, actual calle de San Juan y San Pedro. A. H. Prot. Z. Protocolo de Juan Arruego, 1536, f. 596 v.-600. Publicado en: Manuel Abizanda y Broto, Documentos para la historia artística y literaria de Aragón procedentes del Archivo de Protocolos de Zaragoza: siglo XVI, Zaragoza, La Editorial, 1915-1932, 3 vols., vol. 1, p. 306-307.

14. A. H. Prot. Z., Protocolo de Juan Arruego, 1537, f. 204 y cuaderno. Publicado en: Abizanda, op. cit., vol. 1, p. 315-317.

15. Ibid., 1537, f. 205-212 v. Publicado en: Abizanda, op. cit., vol. 1, p. 308-312.

16. Ibid., 1537, f. 212 v.-213 v. Publicado en: Abizanda, op. cit., vol. 1, p. 312-313.

17. Se le documenta por primera vez el 13 de junio de 1506 (A. H. Prot. Z., Protocolo de Juan Abat, 1506/1507, f. 107 v. y Registro de Juan Abat, 1506/1507, f. 48-48 v. Vid. Manuel-José Pedraza-Gracia, Documentos para el estudio del libro en Zaragoza entre 1501 y 1521, Zaragoza, Centro de Documentación Bibliográfica Aragonesa, 1993, doc. 391), cuando Jorge Coci le nombra procurador, prácticamente desde el comienzo de su actividad en solitario, y desde este momento siempre aparece relacionado profesionalmente con el impresor de origen alemán. Bartolomé de Nájera es uno de los criados de confianza de Jorge Coci, la persona que realiza los negocios de la imprenta y venta de libros en su nombre fuera de Zaragoza y el que se dedica a gestionar la librería propiedad de Coci situada en la calle Botigas Fondas, como él mismo reconoce en el acto realizado en 1536 por el que le vende la mencionada librería: ...Attendient y considerant vos, el honrrado Bartholome de Najara, librero, criado, factor y procurador mio... habeys tratado, negociado, comprado y vendido bienes, libros e mercaderias mias, assi en las ferias de Medina del Campo, como en Leon, y en Francia, y en Valencia y aqui en Caragoça... (A. H. Prot. Z. Protocolo de Juan Arruego, 1536, f. 596 v.-600. Publicado en: Abizanda, op. cit., vol. 1, p. 306-307. 
Zaragoza. Pero el fallecimiento de Pablo Hurus obligó a Coci a hacerse cargo de la mitad de la imprenta que le había vendido. Por esta causa, el 27 de octubre de 1539 Jorge Coci, que quiere desvincularse por completo de sus negocios, vende al notario zaragozano Pedro Bernuz:

...toda la parte e porcion que yo tengo, que es la metad de la emprenta de la dicha ciudad, como son prensas, letras, estanyo obrado por obrar, y caxas para componer, matrices, punzones, instrumentos para fundir e buydar letras, notas de canto, fusillos para prensar y para ramas, cinco camas fornescidas de ropas, y cinco caxones, y dos caxas pequenyas de toda la ferramienta, vaxillos, barrenas, scoplos y otras ferramientas que hazen e pertenescen para la arte y exercicio de la dicha emprenta, y de todas las figuras de fusta como de metal, chicas y grandes y de una taça de plata con la qual se sirven los hombres exercedientes en dicha emprenta. Et assi mesmo la metad de todo lo otro que esta en la casa de dicha emprenta sita en la parrochia de Sant Miguel de los Nabarros de Caragoça... ${ }^{18}$

En este segundo acto de compraventa se incluye una relación de lo que contiene la imprenta prácticamente copiada de la que figura en la primera, cuyos compradores, como ya se dijo, eran Nájera y Hurus.

Pero, ¿qué es lo que lleva a Jorge Coci a vender esta parte de la imprenta a Pedro Bernuz? Pedro Bernuz era un notario zaragozano, descendiente de una familia de notarios de caja de Zaragoza originaria de la localidad de Molinos, en Teruel, que estaba casado con una sobrina de la esposa de Coci, llamada también Isabel Rodríguez ${ }^{19}$. Esta segunda, Isabel Rodríguez era hija del citado Pascual Rodríguez. Sus tíos, Jorge Coci e Isabel Rodríguez fueron también testigos en las capitulaciones de su primer matrimonio con uno de los trabajadores de la imprenta, el oficial de la misma, Juan Agust, de quien debió enviudar pronto. En sus capítulos matrimoniales con Bernuz se la menciona como Isabel Rodríguez, alias Coci y, en ellos, recibió una dote de 14.000 sueldos, una fortuna para la época ${ }^{20}$. La relación de la sobrina con sus tíos fue muy estrecha, tanto por la enorme cuantía de la dote como por el hecho de que se le aplicase el alias de Coci, lo que significa que entre sus convecinos, y con el consentimiento de Jorge Coci y su esposa, se le equiparaba con una hija.

Resulta evidente que sin el conocimiento de la relación familiar de las dos Isabel Rodríguez el vínculo de dos de los empresarios de la imprenta zaragozana más importantes del siglo XVI, Coci y Bernuz, no sería fácil de comprender, especialmente por lo que de sucesión real en la imprenta supuso esta conexión. No son pocas las producciones de Bernuz que hallan un precedente en las de Coci; es también fehaciente el uso sucesivo de los recursos tipográficos; $y$, por supuesto, la semejanza de la marca tipográfica.

18. A. H. Prot. Z., Protocolo de Pedro Martínez de Insausti, 1539, f. 485-488. Publicado parcialmente en: Abizanda, op. cit., vol. 1, p. 313-314.

19. Sus capítulos matrimoniales se firman en Zaragoza el 25 de noviembre de 1533 (A. H. Prot. Z., Protocolo de Salvador Avizanda, Protocolo de 1533, f. 704-716).

20. Ibidem. 
Pero lograr una adecuación jurídica a los deseos de Jorge Coci, no fue fácil. Para conseguir la persecución del máximo de seguridad para los compradores fue preciso forzar la mutación de los participantes en el negocio. En efecto, el 8 de marzo de $1540^{21}$ Pedro Bernuz e Isabel Rodríguez cancelaron con Jorge Coci la compraventa realizada el año anterior; e inmediatamente después Jorge Coci vendió, por tercera vez, la mitad de la imprenta al clérigo Antón Bernuz, tío de Pedro Bernuz ${ }^{22}$. La intervención de este clérigo, que servirá desde este momento como intermediario, perseguía un objetivo evidente: evitar las posibles acciones que los herederos legales de Jorge Coci, esto es, su cuñado Pascual Rodríguez y el resto de sus hijos, pudiesen ejercer contra los nuevos propietarios de la imprenta, especialmente en lo referente a la utilización de la marca de Coci. Antón Bernuz fue el propietario nominal de la mitad de la imprenta hasta que estos problemas se resolvieron por completo, pero el copropietario que ejerce la dirección de la imprenta juntamente con Bartolomé de Nájera es Pedro Bernuz desde el principio. Ambos impresores, Bernuz y Nájera, imprimieron desde 1540 firmando solidariamente sus obras e indicando que se realizaban en la casa de Jorge Coci. Esta situación continuó hasta 1547. Paralelamente, Nájera mantiene el negocio de la librería y Bernuz sigue ejerciendo como notario.

En 1547, un año antes de su muerte, Coci hace donación a Bernuz e Isabel Rodríguez y al resto de los sobrinos de su esposa de ciertos bienes inmuebles solucionando así los problemas sucesorios. Inmediatamente después de solucionar los problemas hereditarios se separan los dos impresores, desgajándose de este modo de la casa madre, la anterior de Coci, la porción de imprenta perteneciente a Nájera. Pedro Bernuz continuó utilizando en sus colofones y portadas la indicación en casa de Jorge Coci a costa de Pedro Bernuz, mientras que en los de Nájera figuraba únicamente en casa de Bartolomé de Nájera. La primera de las obras impresas por Bernuz en solitario es la obra de Alonso López de Corella, Secretos de philosophia y astrologia y medicina y delas quatro matematicas sciencias. En ella firma en el colofón como: Fue impressa la presente obra enla muy noble y leal ciudad de Caragoça enlas casas de George Coci a costas de Pedro Bernuz. Acabose a quinze del mes de Julio. An[n]o de Mil y quinientos y cuarenta y siete 23 .

Pedro Bernuz e Isabel Rodríguez acabaron siendo los herederos universales de su tía y de Jorge $\operatorname{Coci}^{24}$. Fueron enterrados en la capilla instituida por Jorge

21. A. H. Prot.Z., Protocolo de Pedro Martínez de Insausti, 1540, f. 94-94 v. Publicado parcialmente en: Abizanda, op. cit., vol. 1, p. 313-314. Abizanda, op. cit., confunde la fecha (día 18 de marzo) y el objeto del acto, ya que entiende que se trata de una confirmación de la compraventa realizada el ańo anterior.

22. Antón Bernuz actuó como representante de la familia Bernuz en los capítulos matrimoniales de Pedro Bernuz. A. H. Prot. N., Protocolo de Salvador Abizanda 1933, f. 704716.

23. Juan Manuel Sánchez, Bibliografía aragonesa del siglo XVI, Madrid, Imprenta Clásica Española, 1903, 2 vols., n. 259.

24. Vid. Manuel-José Pedraza-Gracia, «La imprenta zaragozana del impresor Pedro Bernuz a través de los protocolos del notario Pedro Bernuz II», Revista de Historia Jerónimo Zurita, 72, 1997 , p. 29-52. 
Coci bajo la advocación de Santa Isabel en el Monasterio Jerónimo de Santa Engracia, donde habían sido enterrados sus tíos, Jorge Coci e Isabel Rodríguez, y otros miembros de la familia de Isabel Rodríguez segunda.

Pedro Bernuz muere en 1571 tras haber creado en sus prensas algunas de las obras más importantes de las producidas en Aragón; pero, a pesar de haber tenido descendencia, seguramente porque su hijo varón, Pedro, no quiso entender en los negocios de su padre, su viuda vendió la imprenta a tres socios: Pedro Sánchez de Ezpeleta, Juan de Alteraque y Gabriel de Híjar. Estos imprimirán por separado durante el último cuarto del siglo XVI, en ocasiones, con los mismos tipos que sirvieron a Pablo Hurus para confeccionar sus producciones.

La relación entre tía y sobrina favoreció el acceso del notario Bernuz a la imprenta, la presencia de estas mujeres tras sus maridos es el hecho desencadenante de la sucesión en la dirección del taller por esta vía. De no haber existido este parentesco, difícilmente el notario Pedro Bernuz segundo hubiese llegado a ser el impresor Pedro Bernuz. Pero, además, es la sobrina la que enajena el negocio que fue de su tío dando lugar a la aparición de tres nuevos nombres en la imprenta zaragozana. Se desconoce si existió una relación de tipo profesional o personal entre los anteriores propietarios de la imprenta y los compradores, por lo que puede mantenerse como hipótesis aceptable que el peso decisivo en esta transmisión fue el económico. Entender la evolución durante un siglo de la que fue la primera imprenta zaragozana estable fundada por Pablo Hurus en el siglo XV hasta la decadencia que se inicia con la venta del taller de la calle de la imprenta en 1571 no sería posible sin la relación de Isabel Rodríguez, esposa de Jorge Coci, y de su sobrina, esposa de Pedro Bernuz, y de la actuación de ésta.

Anna Hurus, Isabel Rodríguez e Isabel Rodríguez, alias Coci jamás firmaron un pie de imprenta, pero sin el conocimiento de su existencia y sus relaciones familiares con los empresarios-impresores zaragozanos la evolución del taller de la Calle de la Imprenta de Zaragoza durante un siglo no sería comprensible.

\section{LAS VIUDAS IMPRESORAS}

Al contrario que Isabel Rodríguez, alias Coci, cuando decidió deshacerse del Negocio de Bernuz, otras muchas viudas de impresores intentaron y, en ocasiones consiguieron, continuar con los negocios de sus maridos.

El caso más destacado es el de Juana Millán, la primera impresora del Reino de Aragón ${ }^{25}$.

En 1531 Pedro Hardouin contrajo matrimonio con Juana Millán, viuda del labrador Lorenzo Rose ${ }^{26}$. En sus capítulos matrimoniales Hardouin aporta al

25. Un trabajo monográfico sobre Juana Millán fue publicado en 2009. Vid. Pedraza, Juana Millán, op. cit. lo referido aquí a esta impresora es un resumen actualizado de ese trabajo.

26. A.H.Prot.Z., Protocolo de Luis Navarro, 1531, f. 90 v. y ss. Publicado parcialmente en: Abizanda, op. cit., vol. 1, p. 330-331. 
matrimonio la imprenta que había abierto tres años antes y que pasa a ser un bien común. En noviembre de 1535 Hardouin es apresado por la Inquisición por lo que Juana Millán asume la actuación de empresaria impresora. Mientras espera su juicio, en 1537, Hardouin testa a favor de Juana Millán otorgándole poderes generales ${ }^{27}$; falleció al poco tiempo cumpliendo la sentencia de galeras a la que fue condenado. En noviembre de 1538 la casa impresora Hardouin publica un Hortulus passionis, cuyo pie de imprenta es el siguiente: In officina que dicitur de Iuana milliana. Vicesima quarta. Me[n] sis Noue $[\mathrm{m}]$ bris vigilia sancte Catherine. An[n] o natiuitate $d[\mathrm{omi}] n i$. M.D.xxxvij ${ }^{28}$. Este pie de imprenta tiene especial importancia, ya que se trata de la primera ocasión en la Península Ibérica en la que una mujer aparece con su propio nombre como responsable de la impresión de un libro. Sin embargo, no era el primer impreso producido bajo la dirección de Juana, según se desprende de un albarán de diciembre de $1536^{29}$. Este documento da a conocer tres impresiones desconocidas de 1536 de la imprenta de Hardouin y confirma que las últimas producciones firmadas por él en 1536 fueron confeccionadas bajo la dirección de Juana.

Juana Millán dicta sendos testamentos el 30 de marzo de $1541^{30}$ y el 10 de abril del año siguiente ${ }^{31}$ encontrándose enferma, por los que lega la imprenta al sobrino de su marido, Luis Hardouin, que trabajaba a su servicio.

El 7 de julio de 1544 Juana Millán capitula su matrimonio con el impresor Diego Hernández. Juana Millán aportaba al matrimonio ...una cassas suyas donde aposenta... y ...todos y qualesquiere otros bienes assi mobles como sitios, emprenta y otros qualesquiere suyos... ${ }^{32}$ y Hernández todos sus bienes. Diego Hernández había sido previamente oficial en Valencia con Francisco Díaz Romano $^{33}$. Juana redacta un nuevo testamento el 5 de agosto de $1545^{34}$ y otro más el 13 de mayo de $1548^{35}$. En este último nombró usufructuario a Diego Hernández, y, de nuevo, heredero del negocio de la imprenta a Luis Hardouin. El 10 de agosto de 1548, Luis Hardouin e Isabel de Morales, hija de Pedro Morales de Villasante y Gracia Millán, capitulan su matrimonio en presencia de Juana Millán, tía de la contrayente y Diego Hernández ${ }^{36}$. Luis Harduin muere en 1549 dejando heredera universal a Juana Millán ${ }^{37}$.

27. A.H.Prot.Z., Protocolo de Martín de Blancas, 1531, f. 574-574 v.

28. Sánchez, op. cit., n. 208.

29. A.H.Prot.Z., Protocolo de Pedro López, 1536, f. 356-356 v.

30. A.H.Prot.Z., Protocolo de Martín de Blancas, 1541, f. 270-275 v. La misma cláusula con respecto a la imprenta figura en un segundo testamento realizado el año siguiente (Ibid., 1542, f. 182 y cuaderno. Cf. Pedraza, Documentos, op. cit., p. 13, nota 40.

31. Ibid., 1542, f. 182 y cuaderno.

32. A.H,Prot.Z. Protocolo de Martín de Morales, 1544, f. 124 v.-127.

33. Cf. Philippe Berger, Libro y lectura en la Valencia del Renacimiento, Valencia, Edicions Alfons el Magnànim, 1987, 2 vols., vol. 1, p. 37, nota 1.

34. A.H.Prot.Z. Protocolo de Juan Campi, 1545, f. 400 v. -405 v.

35. A.H.Prot.Z., Protocolo de Sebastián Moles, 1548, f. 310-313. Cf. Pedraza, Documentos, op. cit., p. 13, nota 40.

36. A.H.Prot.Z., Protocolo de Martín de Blancas, 1548, f. 397 v.-401.

37. Ibid., 1549, f. 7 v. -8 bis y 77 v. -79 v. 
Diego Hernández tampoco sobrevivirá a su esposa. El 25 de enero de 1549 Hernández dictó su testamento ${ }^{38}$, en el que nombró heredera universal a su mujer, y falleció el 3 de febrero ${ }^{39}$. De hecho, sus últimas producciones tienen como fecha el 8 de diciembre de $1548^{40}$. Es la segunda ocasión en la que Juana tiene que ocuparse del negocio, y en julio de 1549 termina la impresión de la obra de Francisco de Osuna, Pars meridionalis, en cuyo colofón figura como Impressi Caesaranguste in aedibus Ioa[n]ae Millian, Viduae Didaci Hernández quondam. Anno humanae salutis. Millesimo Quingentesimo Quadragesimo Nono. Mense Ivli ${ }^{41}$. Desde 1549 se documenta a Juana Millán gestionando su negocio.

El día 4 de julio de 1550 Juana Millán hizo su último testamento ${ }^{42}$, y el día 28 , ya en su lecho de muerte, lo amplió con un codicilo ${ }^{43}$. En estos últimos actos sucesorios Juana Millán, que no tenía descendencia con ninguno de sus tres maridos, ni familiares próximos de ellos, nombró herederos entre su propia familia. Especialmente lega a:

...Joan Millan, sobrino mio, hijo del dicho Agustin Millan, mi hermano, las casas de mi habitacion y emprenta dentro d'ellas stantes... si el dicho Joan Millan morira sin hijos legittimos y de legittimo matrimonio procreados, que las dichas casas y enprenta por mi a el dexadas venga y recayga en el dicho Augustin Millan, su padre, si vivo sera... ${ }^{44}$

El reconocimiento del cadáver de Juana Millán tiene efecto el 8 de agosto de 1550 en la casa en la que se encontraba la imprenta, situada en la parroquia de la Seo ${ }^{45}$. Quien se ocupó de la imprenta fue su hermano, Agustín. Juana Millán no sabía escribir, por lo que siempre necesitó a alguien en quien apoyarse cuando acudía a realizar ante notario negocios de importancia. Agustín Millán, primero, hasta 1564, y su hijo Juan Millán, después, heredero nombrado de la imprenta, hasta 1577, continuaron imprimiendo en ella.

Juana Millán es la primera mujer que pone su nombre en el pie de imprenta de un libro estampado en la Península "In officina que dicitur de Iuana milliana» ${ }^{46} \mathrm{y}$ fue la señora de la imprenta desde 1535 hasta su segundo matrimonio en 1544 y tras el fallecimiento de Hernández en 1549 hasta su propia muerte. Sin Juana, la imprenta debería haber pasado a Luis Hardouin, pero ella persiguió por todos los medios que, sin apartar de su derecho al sobrino de Pedro Harduin, la imprenta quedase en manos de su familia por medio del matrimonio de Luis con su sobrina, Isabel de Morales Millán. El fallecimiento de Luis abrió

38. A. H. Prot.Z., Protocolo de Sebastián Moles, 1549, f. 26 v.-32 v. Cf. Pedraza, Documentos, op. cit., p. 13, nota 40.

39. Ibid., f. 47 v. Cf. Pedraza, Documentos, op. cit., p. 13, nota 40.

40. Bartolomé Cucala, Baculus clericalis, Sánchez, op. cit., n. 277.

41. Sánchez, op. cit., n 290.

42. A.H.Prot.Z., Protocolo de Sebastián Moles, 1550, f. 298 y cuaderno. Cf. Pedraza, Documentos, op. cit., p. 13, nota 40.

43. Ibid., 1550, f. 304-305 v. Cf. Pedraza, Documentos, op. cit., p. 13, nota 40.

44. Ibid., 1550, f. 298 y cuaderno. Cf. Pedraza, Documentos, op. cit., p. 13, nota 40.

45. Ibid., 1550, f. 304. Cf. Pedraza, Documentos, op. cit., p. 13, nota 40.

46. Sánchez, op. cit., n. 208. 
la puerta a que la saga Millán se instalase en la imprenta zaragozana hasta muy avanzados los ańos setenta por medio de su hermano y su sobrino.

Por consiguiente, Juana Millán es, quizás, la representante más destacada de la participación de la mujer en la historia de la imprenta hispana. Gestionó la imprenta de sus difuntos maridos, es la primera impresora en los reinos hispánicos que coloca su nombre propio en sus obras, y debido a su propia peripecia vital derivó la propiedad de la imprenta de Luis Hardouin, sobrino de su esposo difunto, a Agustín Millán, su hermano, y posteriormente a Juan Millán, hijo de Agustín.

La evolución de la imprenta de Hardouin desde 1528 hasta el último tercio de siglo no hubiese sido la misma si Juana Millán no hubiese decidido continuar el trabajo de su marido ayudada, sin duda, por su hermano Agustín.

Tras la ruptura en el taller de la calle de la imprenta entre Bartolomé de Nájera y Pedro Bernuz en 1547 en la compañía de facto en la gestión de la imprenta de Coci, y a pesar de los problemas que le llevaron a vender la imprenta en 1551 a su cuñado, el librero Miguel de Solorzano, Bartolomé de Nájera, no interrumpió en ningún momento su actividad impresora en su propia imprenta.

El 23 de junio de 1523 en Zaragoza, el entonces librero Bartolomé de Nájera y María Solorzano, acompañada de su hermano, el también librero Miguel de Solorzano, naturales de Medina del Campo, firmaron sus capítulos matrimoniales.

El 15 de junio de 1556 Bartolomé de Nájera dictó un testamento en el que nombró herederas universales a Ana e Isabel de Nájera, hijas del testador y de María de Solorzano, a las que ordenó se les diese todo lo que les debería corresponder por sus capítulos matrimoniales. El impresor nombró albaceas a su esposa, María de Solórzano, y a su cuñado, Miguel de Solorzano ${ }^{47}$. También, el 19 de febrero de 1557, dictó testamento Miguel de Solorzano, ...estando doliente de grave enfermedad... en el que nombró ejecutor testamentario, junto con su mujer, Catalina Díez, a su hermana, María Solorzano, y a su cuñado, el impresor Bartolomé de Nájera ${ }^{48}$. En la ejecución testamentaria, el día 5 de marzo, de este testamento se reconoce ...que todos los libros y adretos de la libreria que estan en la botiga de unas casas... sitas en la parroquia de San Pedro... quedasen para el dicho Bartolome de Najera para hazer y disponer d'ellos a toda su voluntad... ${ }^{49}$

De nuevo se encuentran reunidos los negocios de librería e imprenta, en este caso, en manos de una misma familia.

La última obra conocida que firmada por Bartolomé de Nájera está fechada en 1556; se trata del Tractatus sacerdotalis de Blony ${ }^{50}$. Hasta 1562, año en que

47. A.H.Prot.Z., Protocolo de Bartolomé Malo, 1556, f. 265v.-268.

48. Ibid., 1557, f. 58-59 v.

49. Ibid., 1557, f. 74-76.

50. Sánchez, op. cit., n. 385, con dudas; pero cf. el ejemplar con signatura H-8-63 de la Biblioteca Universitaria de Zaragoza. 
comienza a figurar en las obras salidas del taller de la parroquia de San Miguel la mención viuda de Bartolomé de Nájera, nada se conoce del mismo, por lo que se puede establecer sobre estas dos fechas el fallecimiento del impresor. Desde este momento María de Solorzano se hace cargo del negocio, que alcanzará gran importancia por la selección de las producciones del taller.

El 18 de enero de 1564 la hija de Bartolomé de Nájera, Ana de Nájera, y Juan Francés (o Franco) firmaron sus capitulaciones matrimoniales. En ellos, María de Solorzano entrega a Ana para su matrimonio unas casas en la parroquia de San Miguel, reservándose, empero, una habitación,

...para el exercicio de la emprenta que en ellas tiene, en las quales casas para ella y para sus familias pueda tomar todo lo que habra menester tambien para el exercicio de la emprenta... ${ }^{51}$

Algunos años más tarde, el 7 de mayo de 1567, María de Solorzano, viuda de Bartolomé de Nájera, vendió a Vicente de Olona e Isabel de Nájera la imprenta por 10.000 sueldos dineros jaqueses ${ }^{52}$. Sin embargo, se producen algunos problemas en torno a la propiedad de la imprenta, ya que el 11 de junio del año siguiente María de Solorzano, viuda de Bartolomé de Nájera, y su hija Isabel de Nájera y su marido, el médico Vicente de Olona, por una parte, y Ana de Nájera y su esposo, Juan Franco, por otro, nombraron árbitros para dirimir las diferencias existentes entre ellos ${ }^{53}$. Estas diferencias se forjaron, sin duda, a causa de la anterior venta del negocio familiar, la imprenta, que tras este momento figura entre los bienes correspondientes a Ana de Nájera. De esta manera, el 17 de agosto de 1573, cuando Ana de Nájera realiza sus capítulos matrimoniales con el médico zaragozano Juan de Rojas, se reconoce como dueña de la imprenta.

La última obra que firma María de Solorzano como viuda de Bartolomé de Nájera es el Therapevtica metodo de Galeno en lo que toca a Cirurgia, de Jerónimo Murillo, fechada en 1572.

María de Solorzano tiene verdadera importancia en la historia de la imprenta, pero su actividad como impresora, si se analizan las circunstancias que la obligaron a hacerse cargo del taller, estuvo forzada por el interés de transmitir el negocio familiar a sus hijas.

El sobrino de Bartolomé de Nájera, Esteban G. de Nájera, había sido oficial de la imprenta de Coci y se encuentra documentado en el taller desde 1540, cuando Bernuz y Nájera se ocuparon de ella ${ }^{54}$. Por tanto, la suposición lógica es que la nueva imprenta que surge bajo su dirección en 1550 en la calle Mayor de Zaragoza se desgajó de la porción que correspondió a Bartolomé de Nájera de la imprenta de Jorge Coci.

51. A. H.Prot.Z., Protocolo de Bartolomé Malo, 1564, f. 22-30 v.

52. A. H.Prot.Z., Protocolo de Martín Sánchez del Castellar, 1567, f. 120-121.

53. A. H.Prot.Z., Protocolo de Pedro Sancho, 1568, f. 433-435 v.

54. A. H.Prot.Z., Protocolo de Pedro Bernuz II, 1540, f. 35. Vid. Pedraza, «La imprenta zaragozana del impresor Pedro Bernuz...", op. cit., p. 29-52. 
El 17 de mayo de 1548, Esteban de Nájera había realizado sus capítulos matrimoniales con Águeda de Salcedillo ${ }^{55}$. La imprenta de Esteban estaba situada en la Calle Mayor, en Barrionuevo, e imprimió con su sello hasta 1559, primero con el nombre de Esteban y, posteriormente, con el de su viuda, Águeda de Salcedillo ${ }^{56}$, que jamás firmó con su propio nombre.

El 4 de febrero de 1559 Esteban dictó su testamento ...estando enfermo de grave enfermedad de la qual temo morir..., en el que nombró herederos universales a sus hijos, ordenó que se pagase a su hermano, el impresor Diego de Nájera, sesenta libras por los sueldos que le debía hasta ese momento por su trabajo en la imprenta y le nombró especialmente ejecutor testamentario:

Encargo al dicho Diego de Najera, mi hermano, que tenga tambien por encomendados a los dichos mis hijos y les ayude... en todo lo que pudiere como buen hermano que se quede en compañia de mi mujer y hijos con el exercicio de la emprenta y botiga para que mi mujer e hijos puedan vivir y el gane sus soldada como la ganaba con mi o como se concertare con la dicha mi mujer... ${ }^{57}$

Diego de Nájera ha sido documentado como oficial de la imprenta de Bernuz y Bartolomé de Nájera en los años 1544 y $1545^{58}$; debe de ser el mismo impresor que figura en 1564 en Alcalá de Henares ${ }^{59}$. Diego fue, sin duda, el artífice que se responsabilizó de la imprenta durante los primeros momentos tras la muerte de su hermano hasta que su cuñada contrajo nuevo matrimonio con el librero Miguel de Huesa, que comenzó a firmar las obras salidas de esta imprenta desde $1562^{60}$. Águeda de Salcedillo dictó testamento el 18 de junio de $1577^{61}$ nombrando heredera en lo que hace a los bienes que le correspondiesen de Esteban de Nájera a su hija Ana de Nájera; y, del resto de sus bienes, a su segundo esposo, Miguel de Huesa.

Miguel de Huesa, el 12 de septiembre del mismo año ${ }^{62}$, habiendo muerto Águeda de Salcedillo, trasmitió la propiedad de la imprenta a sus hijos y, posteriormente, como su tutor vendió al librero Hernando de París ...la sobre dicha emprenta de imprimir libros que fue de la quondam Agueda de Salcedillo con sus matrices y con todos sus aparejos... por 7.200 sueldos. Miguel de Huesa dejó de imprimir en 1577 para volver a dedicarse a la librería, su anterior profesión.

55. A.H.Prot.Z., Protocolo de Bartolomé Malo, 1548, f. 169 v.-170.

56 . El 3 de abril se encuentra documentada realizando negocios con el librero soriano Bernabé Díez (Ibid., 1559, f. 48-49 v.).

57. Ibid., 1559, f. 22 v.-24.

58. Vid. Pedraza, «La imprenta zaragozana del impresor Pedro Bernuz...», op. cit., p. 29-52.

59. Cf. Julián Martín Abad, La imprenta en Alcalá de Henares (1502-1600), Madrid, ArcoLibros, 1991, 3 vols.

60. En 1562, el 8 de septiembre dicta testamento el padre de Águeda de Salcedillo, en el que nombra ejecutor a sus yernos, entre los que se encuentra Miguel de Huesa, casado con Águeda de Salcedillo, viuda de Esteban de Nájera (A.H.Prot.Z., Protocolo de Bartolomé Malo, 1562, f. 265-267 v.).

61. A.H.Prot.Z., Protocolo de Cristóbal Navarro padre, 1577, f. 720-722v.

62. Ibid., 1577, f. 1.097v.-1.102. 
De nuevo se vuelve a repetir el proceso que llevó a Hernández a dirigir la imprenta de Hardouin, la viuda de un impresor, en este caso Águeda contrae nuevo matrimonio con un artesano del libro, Miguel de Huesa, que conoce el negocio, lo que lleva a que este segundo marido se haga cargo de la imprenta.

El caso de la viuda de Juan de Villanueva es un caso especial. En realidad, las primeras noticias que se poseen de Juan de Villanueva proceden de Alcalá de Henares, ciudad en la que imprime entre 1565 y 1576, y de allí se traslada, a tenor de los libros que firma, a Lérida. En ambas localidades imprime asociado con Pedro de Robles. Nunca firmó un libro en Zaragoza. Sin embargo, su viuda firma en sociedad con Juan Soler uno en 1577 en esta ciudad. La única obra en la que figura es la edición de Las comedias de Terencio de esa misma fecha ${ }^{63}$ que se realizó en virtud de un contrato de compañía preexistente:

Nosotros, Luysa Loppez, viuda relicta del quondam Joan de Villanueva, impresor de libros, de una parte, y Joan Soler, impresor de libros, vezinos de la ciudad de Caragoça, de la parte otra, revocando, cassando y annullando quales quiere conciertos y capitulaciones entre nosostros hata el dia de hoy, por razon de la companya de impresión hechos, agora de nuevo de grado etc. hazemos y ordenamos la presente concordia entre nosotros tractada y concerta... ${ }^{64}$

Pero en ninguna obra figura con su nombre, Luisa López. Su actividad como impresora culminó abandonando la sociedad para arrendar el 5 de agosto de 1577 el material de imprenta que poseía de su esposo a su socio, el impresor Juan Soler:

Et primeramente es pactado y concertado entre nosotros, dichas partes, que yo, dicha Luysa Perez, haya de arrendar y arriende, segun que por tenor del presente arriendo a vos, dicho Joan Soler, la prensa de la emprenta que yo tengo con las cosas conexas a ella por tiempo de dos ańos continuos del presente diya de hoy adelante contaderos; por precio en cada un anyo de diez y ocho escudos, que fazen suma de trezientos y sesenta sueldos jaqueses. Empero, es condicion que yo, dicha Luysa Lopez, he de dexar cosufructuar la letra al dicho Joan Soler de aqui al dia de Navidad proxime venidero con todos los demas aparejos de la composicion y no por mas tiempo ni porcion que fuere ${ }^{65}$.

De manera similar ocurre con la viuda de Juan Escarrilla, que interviene en el mundo de la imprenta asociada al impresor Pedro Puig, aunque, en este caso, el impresor ya era socio de su esposo.

El impresor Juan de Escarrilla firmó junto con Pedro Puig en 1587 y 1588 varias obras en su taller, situado junto a la Plaza del Pilar, en Zaragoza. En esa última fecha comienza a aparecer la mención de la viuda de Ioan de Escarrilla en las obras surgidas del mismo taller junto al nombre de su socio Puig. Nunca firmó con su nombre, Juana Rodríguez. Por primera vez figura en la Historia eclesiastica de Pedro de Ribadeneira ${ }^{66}$. Desaparece de los colofones y portadas de

63. Sánchez, op. cit., n. 533

64. A.H.Prot.Z., Protocolo de Sebastián Moles menor, 1577, f. 505 v.-508 v.

65. Idem.

66. Sánchez, op. cit., n. 685. 
las producciones de la imprenta zaragozana en 1590 imprimiendo en solitario, una vez disuelta la compañía con Puig con la siguiente indicación: En casa de la Viuda de Ioan Escarrilla, En la Cuchilleria ${ }^{67}$. El año siguiente Juana Rodríguez contrae matrimonio con el impresor Miguel Ximeno Sánchez ${ }^{68}$, que continúa imprimiendo hasta finales de siglo.

Juana Rodríguez es la tercera viuda impresora que contrae matrimonio con otro impresor, Miguel Ximeno Sánchez, que se hace cargo del taller imprenta.

\section{LA hiJa del impresor, ANa de Nájera}

Como se ha visto en el apartado anterior, al tratar de su madre, Ana de Nájera figura ya como propietaria de la imprenta el 18 de enero de 1564, cuando firma sus capitulaciones matrimoniales con Juan Francés (o Franco). El 17 de agosto de 1573, cuando Ana de Nájera realiza sus capítulos matrimoniales con el médico zaragozano Juan de Rojas, estipula en el tercer y cuarto capítulos lo siguiente:

...Item, trae mas la dicha Ana de Nagera todo el officio de la emprenta con todos los instrumentos, matrizes, caracteres y prensas, y otras cosas y manefiçios concernientes al dicho officio de la emprenta, todo lo qual esta stimado y se stima en precio y valor de veinte mil sueldos dineros jaqueses... Item trae mas todos los libros imprimidos de qualquiere profession y sciencia que sean stantes en la botiga questa en la sala de verano de las dichas casas, los quales han sido stimados y se stiman en precio de diez mil sueldos dineros jaqueses... ${ }^{69}$

El 20 de noviembre de 1573, el nuevo matrimonio, Ana de Nájera y Juan de Rojas, vende al librero Pedro Sánchez de Ezpeleta:

...la emprenta y aparejos de imprimir nuestros con todos los maneficios nuestros y cosas a ella pertenescientes y necessarias como son: prensas, matrizes, caracteres, moldes, letras, arcas, numeros, cajas de composicion, olla de arambre, tinajas y otras cosas tocantes y necessarias al uso y exercicio de la dicha emprenta; y mas todos los libros de la botiga de la dicha emprenta de qualquiere genero y specie de escriptura que sean assi en latin como en romançe, nuebos y viejos, buenos y malos, con todos los estantes y tablas en que agora stan puestos, francos y quitos de toda obligacion, censo, trehudo, censal, obligación, sevitud y toda mala voz etc. con todos los drechos y actiones actos y a cadauno de nos en lo sobre dicho pertenescentes etc. por precio de quarenta mil sueldos dineros jaqueses... ${ }^{70}$

El mismo día Pedro Sánchez de Ezpeleta reconoció tener una deuda de 40.000 sueldos dineros jaqueses con Ana de Nájera y Juan de Rojas, cuyo pago avaló el infanzón Gabriel de $\mathrm{Hijar}^{71}$. También se especificó la forma de pago

67. Ibid., n. 707.

68. A.H.Prot.Z., Protocolo de Lorenzo de Bierge, 1591, f. 984 y ss.

69. A.H.Prot.Z., Protocolo de Martín Sánchez del Castellar, 1573, f. 281 y cuaderno al final del protocolo.

70. Ibid., 1573, f. 422-422 v.

71. Ibid., 1573, f. 422 v. -423 v. 
en una de cuyas variantes Gabriel de Híjar se comprometió a entregar medio censal que posee de 500 sueldos de pensión y 10.000 sueldos de propiedad ${ }^{72}$.

Todo esto lleva a sospechar que el responsable de la imprenta fue Juan Franco (o Francés), aunque Ana de Nájera mantuvo la propiedad del negocio. Se conocen muy pocas obras impresas bajo el nombre de Ana de Nájera, todas realizadas en $1573^{73}$.

\section{A MODO DE CONCLUSIÓN}

La importancia del estudio de las mujeres en relación con la imprenta y el libro es capital para entender el desarrollo de los talleres de imprenta como un espacio en evolución y poder eliminar su supuesta concepción estática. La mujer en este mundo ocupa diversas posiciones.

No se encuentran representantes femeninos que por decisión propia se encarguen de un taller. La mujer aparece en las fuentes de información sobre la imprenta como esposa de los impresores y, cuando se produce la ausencia o el fallecimiento del esposo, adquieren la posesión o la propiedad de los talleres.

En unos casos, deciden mantener el negocio y actúan como empresarias de negocios de imprentas. En Zaragoza es el caso de Juan Millán, María Solorzano, Águeda de Salcedillo, Luisa López y Juana Rodríguez. En otras, enajenan la imprenta renunciando a ellas a cambio de cantidades económicas importantes. En Zaragoza es el caso de Isabel Rodríguez, alias Coci. También es posible encontrar mujeres que acceden a esa posición en los talleres por filiación como Ana de Nájera. Tanto en un caso como en los otros se produce la sustitución natural del difunto marido o padre en la función. Si existe un matrimonio o si se produce un matrimonio posterior, es el marido de la heredera propietaria de la imprenta el que se hace responsable de la actividad empresarial. Resultan ser intermediarias en el relevo de impresores en los talleres. La sociedad del libro en la Edad Moderna se construye en ámbitos muy cerrados, lo que facilita la existencia de relaciones familiares entre artífices a través de mujeres: yernos y suegros, tíos y sobrinas... Este es otro de los fenómenos que justifican el estudio de las mujeres, ya que ayuda a comprender la evolución de una imprenta y las causas que hicieron que esta fuese a parar de unas manos a otras. Es el caso de Ana Hurus o Isabel Rodríguez, alias Coci.

En ambas situaciones es preciso que una mujer haga la función de la sustitución o sirva de correa de transmisión. Solo de esta manera se comprende a la perfección la dinámica de la evolución de los talleres de imprenta, porque estos, además de recursos tipográficos, son también personas, muchos de cuyos nombres son absolutamente desconocidos, que simplemente sirvieron a distintos señores y señoras sin cambiar de taller.

72. Ibid., 1573, f. 423 v. -424

73. Cf. Juan Delgado Casado, Diccionario de impresores españoles (siglos XV-XVII), Madrid, Arco-Libros, 1996. 